\title{
Prognosis in adult asthma: a national study
}

\author{
H L J MARKOWE, C J BULPITT, M J SHIPLEY, G ROSE, D L CROMBIE, \\ D M FLEMING
}

\begin{abstract}
Although one million people consult their general practitioners for asthma each year, data on the prognosis of this disease are scarce, particularly in adults. Mortality was studied among 2547 adult asthmatics attending a national sample of 60 general practices between 1970 and 1976; they were compared with a matched group of non-asthmatic patients. Mortality from all causes was significantly raised in the asthmatic cohort (189 deaths $v 112$ among controls; relative risk $1 \cdot 61,95 \%$ confidence interval 1.3 to 2.0 ), especially in women (92 $v 42$ deaths; relative risk $2 \cdot 2(1 \cdot 5$ to $3 \cdot 1)$ ), and in the oldest age group (55-59 years). In both sexes the predominant cause of excess mortality was respiratory disease, particularly asthma (25 $v 0$ deaths) and chronic obstructive airways disease (37 $v 4$ deaths; relative risk $8.8(2.8$ to 23$))$. Overall, $94 \%$ of the asthmatic cohort survived the mean follow up period of eight years compared with $96 \%$ of the controls.

In contrast to previous findings, the risk of death due to malignant neoplasms was not significantly reduced overall (34 $v$ 36 deaths), though the risk was significantly reduced among those aged under 45 years $(2 v 10$ deaths; relative risk $0.2(0.02$ to 0.9$)$ ) and there was a significant trend of lowering of relative risk with younger age $(\mathbf{p}<0.01)$.
\end{abstract}

\footnotetext{
Department of Epidemiology, London School of Hygiene and Tropical Medicine, London WC1E 7HT

H L J MARKOWE, MFCM, MSC, lecturer

C J BULPITT, MD, FRCP, reader

$M$ J SHIPLEY, BA, MSC, lecturer

G ROSE, DM, FRCP, professor

Birmingham Research Unit, Royal College of General Practitioners, Birmingham B17 9DB

D L CROMBIE, MD, FRCGP, director

D M FLEMING, MB, FRCGP, deputy director
}

Correspondence to: Dr H Markowe, Alexander Fleming House, DHSS, Elephant and Castle, London SE1 6BY.

\section{Introduction}

Asthma was the underlying cause of death in 1972 people in England and Wales in 1985, 47\% of these deaths being among people aged under 65 years. ${ }^{1}$ This represents only a small proportion of the $2 \%$ of the population (about 1 million people) who consult their general practitioners for asthma each year. ${ }^{2}$ Rises in asthma mortality have been reported in New Zealand ${ }^{3}$ and the United States, ${ }^{4}$ and although the reality of a similar reported rise in England and Wales ${ }^{5}$ has been questioned, ${ }^{6}$ there is strong evidence of a substantial recent rise in the prevalence of asthma.

Data on the outcome of adult asthma are, however, scarce. Life assurance data are highly selected, ${ }^{7}$ and hospital follow up studies are likely to be restricted to more severe cases and not be generalisable to the community as a whole. ${ }^{89}$ Small numbers and lack of controls have resulted in continuing uncertainty about mortality in asthma. Studies based on general practice have been limited again by small numbers and by geographical restrictions, ${ }^{10}$ and they have often been concerned only with children. ${ }^{11}$

Alderson reported on the mortality of about 2000 adults with asthma who attended a special asthma clinic in Manchester between the late $1930 \mathrm{~s}$ and the early $1950 \mathrm{~s}^{12}$ and compared it with expected deaths based on national rates. He found a significantly increased mortality from all causes (relative risk $=1.58$ ) and a significantly reduced risk of death from malignant disease (relative risk $=0.71$ ). His study, however, was hospital based, included mainly "atopic" asthmatics, and may not reflect the major therapeutic advances of recent years.

We now report on mortality among 2547 adults with asthma identified in 1970-6 in a population which was nationally representative by age, sex, and social class and registered in 60 general practices distributed throughout England and Wales. They were compared with a group of non-asthmatics matched for age, sex, and general practice.

\section{Patients and methods}

The study population was derived from patients attending general practitioners participating in the second national morbidity survey. ${ }^{1314} \mathrm{This}$ survey was set up in 1970 jointly by the Royal College of General Practitioners, the Department of Health and Social Security, and the Office 
of Population Censuses and Surveys. Its main objective was to record consulting patterns in about 290000 people. Sixty general practices participated between 1970 and 1972, and a smaller number continued until 1976. These were not randomly selected but they reflected the national distribution of practices in terms of number of partners, urban or rural catchment areas and regional representation. With the cooperation of local family practitioner committees, a register of patients was compiled for each practice and kept up to date throughout the study, thus representing the "population at risk." The diagnosis (or diagnoses) at every consultation or home visit were recorded on a diagnostic index. In the final three years of the study details were recorded relating only to episodes of illness rather than to individual consultations.

Our study population consisted of 2547 patients aged 25-64 years who were recorded as consulting their general practitioner for asthma during the course of the national morbidity survey. Also studied were a group of controls matched for age (within one year), sex, and practice who had not consulted their general practitioners for asthma during the course of the survey. Controls were randomly selected by the Office of Population Censuses and Surveys from a computer file containing all subjects registered with the 60 general practices after excluding those who had attended for asthma.

The Office of Population Censuses and Surveys provided lists of cases and controls identified only by the first three letters of their surname, first initial, sex, and date of birth. Further information included consultation history and, when relevant, occurrence of death. The last two items related only to the period during which the practice participated in the national morbidity survey.

To increase the length of mortality follow up we sent the lists to general practitioners, requesting details of the full names of subjects, their national health service numbers, and their current status-that is, $(a)$ listed on the current practice register, $(b)$ records returned to the family practitioner committee, or $(c)$ patient known to have died. General practitioners identified subjects using one or more of the following sources; practice agesex registers; original diagnostic indexes; medical record envelopes. Details of subjects not currently on practice registers were forwarded to the National Health Service central register to determine whether they had died, emigrated, or were still alive and, when relevant, for the provision of death certificates. The underlying cause of death was coded according to the ninth International Classification of Diseases. ${ }^{15}$

Person years at risk were calculated for each individual from the date of entry into the second national morbidity survey until the end of follow up. The end of follow up was $(a)$ the date each general practitioner recorded the subject as being alive and on the practice list minus six months (to allow for delay in notifying deaths to general practitioners); (b) 1 October 1985 for subjects registered with the National Health Service central register; $(c)$ the dates of loss to follow up; or $(d)$ the date of death or emigration for subjects identified by the central register as dead or emigrated. Standard methods for the analysis of longitudinal studies were used ${ }^{16}$ : the person years at risk provided the denominator of death rates in both the subjects with asthma and the controls, from which relative risks of death were calculated. Deaths among adults with asthma (cases) were expressed as a proportion of all deaths (cases plus controls) from that cause; $95 \%$ confidence intervals for this proportion were calculated according to the binomial distribution and then adjusted for the difference between cases and controls in person years at risk. Tests of significance for linear trend were performed using the computer program Generalised Linear Interactive Modelling. ${ }^{17}$

\section{Results}

Twenty of the 60 practices did not participate in the study of asthma prognosis. In eight practices the original general practitioner had died, retired, or moved and replacement doctors had declined to participate; in nine practices the original general practitioner declined to participate; and in three cases the original practices no longer existed. Mortality follow up information on subjects registered with these practices-1324 (26\%) of total study subjects - and also on others whom we could not subsequently identify as dead or alive was restricted to deaths occurring during the course of, rather than subsequent to, the national morbidity survey (table I). Among participating practices the "untraceable" subjects arose predominantly from failure of general practitioners to provide any identifying information. This occurred in 328/389 (84\%) of untraceable cases and $443 /$ $501(88 \%)$ of untraceable controls. The remaining untraceable subjects could not be followed up because of insufficient or wrong information.

The remaining tables are based on all 2547 cases and their matched controls. The mean follow up period was 8.4 years in cases and 8.1 years in controls. For the reasons stated above, however, follow up time was essentially bimodal, 1044 cases $(41 \%)$ and 1158 controls (45\%) having no death notification possible after the national morbidity survey (mean
TABLE I-Identification of cases and controls. Values are numbers (percentages)

\begin{tabular}{|c|c|c|}
\hline & Cases & Controls \\
\hline \multicolumn{3}{|c|}{ Non-participating practices } \\
\hline $\begin{array}{l}\text { Died during national morbidity survey } \\
\text { Alive at end of survey }\end{array}$ & $\begin{array}{r}8(0 \cdot 3) \\
654(26)\end{array}$ & $\begin{array}{r}5(0 \cdot 2) \\
657(26)\end{array}$ \\
\hline \multicolumn{3}{|c|}{ Participating practices } \\
\hline $\begin{array}{l}\text { Listed on current practice register } \\
\text { Not listed. but traced by OPCS. }\end{array}$ & $1009(40)$ & $957(38)$ \\
\hline $\begin{array}{l}\text { Not listed, but traced by OPCS: } \\
\text { Dead }\end{array}$ & $181(7)$ & \\
\hline Alive & $287(11)$ & $297(12)$ \\
\hline Emigrated & $16(0.6)$ & $13(0 \cdot 5)$ \\
\hline Other & $3(0 \cdot 1)$ & $10(0 \cdot 4)$ \\
\hline Not listed and untraced by OPCS & $389(15)$ & $501(20)$ \\
\hline Total & $2547(100)$ & $2547(100)$ \\
\hline
\end{tabular}

follow up period about three years), while 1296 cases (51\%) and 1254 controls $(49 \%)$ had mortality notification for the complete period of the asthma study (mean follow up period about 14 years).

Table II shows the age and sex distribution of the 2547 cases and their matched controls. The age was calculated for each individual as age at entry to the national morbidity survey (usually November 1970) plus half the days at risk during the course of the survey. (This method was used by the Office of Population Censuses and Surveys when generating the age matched controls.)

TABLE II-Age and sex distribution of case population ( $n=2547)$ : Values are numbers (percentages)

\begin{tabular}{lccc}
\hline Age & Men & Women & Total \\
\hline$<45$ & $610(53)$ & $707(51)$ & $1317(52)$ \\
$\geqslant 45$ & $537(47)$ & $693(50)$ & $1230(48)$ \\
\hline All ages & $1147(100)$ & $1400(100)$ & $2547(100)$ \\
\hline
\end{tabular}

Table III presents mortality from selected causes in cases and controls. All cause mortality was significantly raised (relative risk 1.61) in the subjects with asthma, predominantly because of large excesses in deaths due to chronic obstructive airways disease and asthma. The subjects with asthma also showed a small non-significant rise in mortality from circulatory disease and a small non-significant fall in mortality from malignant neoplasms.

TABLE III-Causes of death in cases and controls

\begin{tabular}{|c|c|c|c|}
\hline Cause of death (ICD code) & Cases & Controls & $\begin{array}{c}\text { Relative risk } \\
(95 \% \mathrm{CI})\end{array}$ \\
\hline \multirow{10}{*}{$\begin{array}{l}\text { All causes (000-999) } \\
\text { Respiratory diseases (460-519): } \\
\text { Bronchitis, emphysema, asthma, and } \\
\text { chronic airways obstruction not elsewhere } \\
\text { classified (490-496) } \\
\text { Chronic obstructive airways disease } \\
\text { (490-492, 496) } \\
\text { Asthma (493) } \\
\text { Circulatory diseases (390-459): } \\
\text { Ischaemic heart disease (410-414) } \\
\text { Acute myocardial infarction (410) } \\
\text { Malignant neoplasms (140-208): } \\
\text { Malignant disease of trachea, bronchus, and } \\
\text { lung (160-165) } \\
\text { All other malignant neoplasms (140-159, } \\
\text { 166-208) }\end{array}$} & 189 & 112 & $1 \cdot 61^{\star \star}(1 \cdot 3$ to $2 \cdot 0)$ \\
\hline & 70 & 6 & $11 \cdot 1^{\star \star}(4 \cdot 9$ to 32$)$ \\
\hline & 62 & 4 & $14.8^{\star \star}(5.5$ to 56$)$ \\
\hline & $\begin{array}{l}37 \\
25\end{array}$ & $\begin{array}{l}4 \\
0\end{array}$ & $\begin{array}{c}8 \cdot 8^{\star \star}(2.8 \text { to } 23) \\
\infty^{\star \star}(6.0 \text { to } \infty)\end{array}$ \\
\hline & 68 & 53 & $1.2 \quad(0.9$ to 1.8$)$ \\
\hline & 42 & 35 & $1.1 \quad(0.7$ to 1.8$)$ \\
\hline & 33 & 25 & $1.3 \quad(0.7$ to 2.2$)$ \\
\hline & 34 & 36 & $0.90(0.5$ to 1.5$)$ \\
\hline & 11 & 14 & $0.75(0.3$ to 1.8$)$ \\
\hline & 23 & 22 & $1.0 \quad(0.5$ to 1.9$)$ \\
\hline
\end{tabular}

$\star \star \mathrm{p}<0.01$.

Table IV presents mortality from selected causes for men and women separately. The increase in all cause mortality occurred in both sexes, but in men it was less and not significant. The all cause relative risk in women was significantly greater than that in men after allowing for age differences $(p=0.02)$. The sex difference in deaths from cancer was principally due to a pronounced (though non-significant) reduction in deaths from lung cancer in men. Non-neoplastic respiratory deaths were consistently 


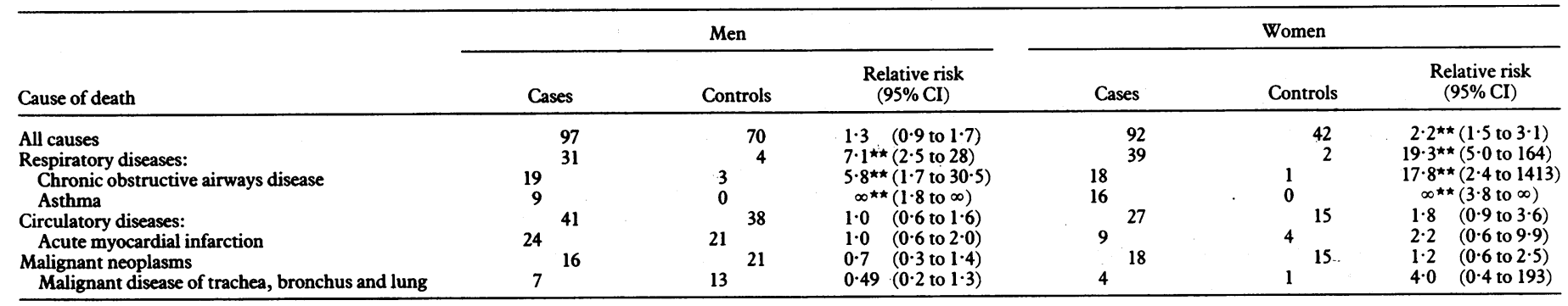

${ }^{\star \star} \mathrm{p}<0 \cdot 01$.

and significantly raised in both sexes (relative risk $7 \cdot 1$ in men; $19 \cdot 3$ in women).

Table $\mathrm{V}$ presents all cause mortality and deaths due to malignant disease in cases and controls according to age. All cause mortality was only slightly and non-significantly raised in the youngest age group, in contrast with the large significant increase present in the older age group. The trend of increasing relative risk with age fell just short of the $5 \%$ level $(p=0 \cdot 07)$. The relative risk of death from cancer was significantly reduced in the youngest age group, and a trend with age was present $(p<0.01)$ in both sexes.

TABLE V-Cause of death in cases and controls, by age

\begin{tabular}{|c|c|c|c|c|c|c|}
\hline \multirow[b]{3}{*}{$\begin{array}{l}\text { Age } \\
\text { group } \\
\text { (years) }\end{array}$} & \multicolumn{6}{|c|}{ Cause of death } \\
\hline & \multicolumn{3}{|c|}{ All causes } & \multicolumn{3}{|c|}{ Malignant neoplasms } \\
\hline & Cases & Controls & $\begin{array}{c}\text { Relative risk } \\
(95 \% \mathrm{CI})\end{array}$ & Cases & Controls & $\begin{array}{c}\text { Relative risk } \\
(95 \% \mathrm{CI})\end{array}$ \\
\hline $\begin{array}{l}<45 \\
45-49 \\
50-54 \\
55-59\end{array}$ & $\begin{array}{r}24 \\
21 \\
28 \\
116\end{array}$ & $\begin{array}{l}20 \\
14 \\
21 \\
57\end{array}$ & $\begin{array}{l}1.1 \quad(0.6 \text { to } 2.2) \\
1.4 \quad(0.7 \text { to } 2.9) \\
1.3 \quad(0.7 \text { to } 2.4) \\
2.0^{\star \star}(1.5 \text { to } 2.8)\end{array}$ & $\begin{array}{r}2 \\
3 \\
7 \\
22\end{array}$ & $\begin{array}{r}10 \\
5 \\
7 \\
14\end{array}$ & $\begin{array}{l}0.2^{\star}(0.02 \text { to } 0.9) \\
0.6(0.07 \text { to } 2.8) \\
1.0(0.3 \text { to } 3.2) \\
1.5(0.8 \text { to } 3.3)\end{array}$ \\
\hline
\end{tabular}

${ }^{\star} \mathrm{p}<0.05 .{ }^{\star \star} \mathrm{p}<0.01$.

\section{Discussion}

The raised all cause mortality (relative risk 1.61) found in the present study was similar to risks of 1.58 and 1.67 reported by two previous cohort studies. ${ }^{12} 18$ These studies were restricted, however, in one case to "atopic" asthmatics attending a single hospital in England and in the other to United States servicemen. By contrast, our findings reflect the experience of a cross section of British adults with asthma attending their general practitioners. The range of disease severity should therefore be wide.

The excess mortality came mainly from asthma, bronchitis, and emphysema. The large relative risk of death from asthma is unsurprising, but it should be emphasised that only $1 \%$ of the total asthmatic cohort died from asthma over the follow up period. The increase in the proportion of deaths from chronic obstructive airways disease accords with previous findings ${ }^{18} 19$ and may indicate initial misclassification of cases, inaccurate death certification, or an increased propensity for asthmatics to develop other respiratory disease (or vice versa). A significant excess of deaths from both asthma and chronic obstructive airways disease was present in both sexes and among both younger ( $<45$ years) and older ( $\geqslant 45$ years) people. Deaths from other respiratory diseases in the asthmatic cohort-bronchopneumonia (5), influenza (1), pneumothorax (1), idiopathic fibrosing alveolitis (1)-also exceeded numbers in the control cohort, there being only two deaths from bronchopneumonia in this category.

In men excess mortality among those with asthma was largely accounted for by respiratory deaths. The previously reported excess risk of death from ischaemic heart disease in male asthmatics ${ }^{18}$ was not confirmed. There were, however, four deaths from cor pulmonale in male asthmatics compared with none in controls. Among women one quarter of the excess deaths among those with asthma were explained by circulatory disease, half of this excess being attributable to a non-significant increase in ischaemic heart disease and the remainder to a variety of causes, including pulmonary embolism (two deaths among cases, none among controls).

It is important to consider whether methodological biases could have contributed to the overall excess risk described. A third of general practices did not participate in the follow up study. Deaths from these practices were nevertheless recorded during the period of their participation in the second national morbidity survey, and when analysis was restricted only to this period the relative risk for the entire 60 practices remained essentially unchanged at 1.65 .

In practices which did participate in the follow up study, identification - and subsequent characterisation of subjects as alive or dead-was less efficient in controls than cases. This mainly reflected less efficient identification of the $25 \%$ of controls who did not consult their doctors during the national morbidity survey. A small proportion of these non-consulting controls would have moved home, emigrated, or died. A validation exercise performed in 1973 estimated that such inflation of the registered practice population was only $3 \% .{ }^{13}$ Restriction of the analysis to the $75 \%$ of controls who did consult their general practitioners and their matched cases resulted in a small reduction in the all causes relative risk to $1.54(\mathrm{p}<0.01)$. As most non-consulting controls were likely to have been healthier than consulting controls, however, the relative risks may have been underestimates.

As rigid diagnostic criteria were not a feature of the national morbidity survey some misclassification of cases may have occurred. Nevertheless, the usefulness of the results is to indicate the prognosis of individuals labelled-correctly or incorrectly-as asthmatic in day to day practice. Three hundred and forty two cases also consulted for emphysema or chronic bronchitis during the course of the national morbidity survey and may have represented "false positive" cases of asthma. Exclusion of these resulted in only a small fall in the all cause relative risk to $1.4(p<0.05)$. As these diseases frequently coexist with asthma, ${ }^{20}$ such a restriction may itself be inappropriate.

Several studies have reported a reduced risk of developing malignancy in subjects with allergic disease. ${ }^{21-23} \mathrm{We}$ found no overall evidence for such an effect, the relative risk for all malignant neoplasms excluding lung cancer being 1 . The two previous cohort studies of asthmatics have produced conflicting findings on this issue, Alderson reporting a significantly reduced risk of malignant disease (relative risk $0 \cdot 71$ ) $^{12}$ and the American study a significantly increased risk (relative risk $1 \cdot 28$ ), ${ }^{18}$ predominantly due to lung and pancreatic cancer. This difference may be attributable to differing smoking and drinking habits. Although many asthmatics smoke, smoking is probably less prevalent than in the general population. ${ }^{24}$ This is likely to account for the reduced risk found for lung cancer in our study among men.

Post hoc subgroup analyses must be interpreted with caution. Nevertheless, stratification by age indicated a significantly reduced risk of death from all malignant neoplasms in the youngest age group and an apparent trend of increasing risk with increasing age. The deficit of deaths in the youngest age group derived from both lung cancer and other neoplasms. The significantly reduced risk of malignant neoplasm reported by Alderson in predominantly "atopic" asthmatics came from study of a younger cohort than 
ours $-70 \%$ of his subjects were aged less than 45 years — and at least in younger asthmatics our findings are consistent with those of Alderson. ${ }^{12}$

Many deaths from asthma are considered to be avoidable, ${ }^{25}$ particularly those occurring at younger ages. ${ }^{26}$ Various strategies have been recommended to prevent such deaths, including improved education of patients in recognising the potential severity of their condition, ${ }^{27}$ better training of general practitioners and hospital doctors in assessing, monitoring, and treating asthma ${ }^{28}$ and the facilitation of hospital admission. ${ }^{29}$ The excess mortality from respiratory disease other than asthma indicates the additional importance of monitoring asthmatics for coexisting respiratory illness. The results further suggest that women and older asthmatics are at greater relative risk of premature death. Overall, however, $\mathbf{9 4 \%}$ of the asthmatic cohort survived the follow up period. Further research into specific characteristics is needed to distinguish between the minority of asthmatics at greatly increased risk of premature death because of their disease and the vast majority not at such risk.

We thank our research assistant Lucy Daly; Kris Ebi-Kryston for her help in data processing; Mr David Birch and staff of the Office of Population Censuses and Surveys; the general practitioners and their assistants who took part in the second national morbidity survey; and the staff of the Birmingham Research Unit of the Royal College of General Practitioners. The study was supported by grants from the Medical Research Council and Asthma Research Council.

\section{References}

1 Office of Population Censuses and Surveys. Mortality statistics 1985. London: Government Statistical Service, 1986. (Series DH2 86/2.)

2 Fleming DM, Crombie DL. Prevalence of asthma and hay fever in England and Wales. Br Med $\mathcal{f}$ 1987;294:279-83.
3 Jackson RT, Beaglehole R, Rea HH, et al. Mortality from asthma: a new epidemic in New Zealand. BrMed f 1982;285:771-4.

4 Sly RM. Increases in deaths from asthma. Ann Allergy 1984;53:20-5.

5 Burney PGJ. Asthma mortality in England and Wales: evidence for a further increase, 1974-84. Lancet 1986; i:323-6.

6 Markowe HLJ. Asthma mortality in England and Wales. Lancet 1986;ii:636.

7 Preston TW Clarke RD. An iny in Engtand and the 1947-63. Fournal of the Institute of Actuaries 1966;92:27-74.

8 Ogilvie AG. Asthma: A study in prognosis of 1000 patients. Thorax 1962;17:183-9.

9 Pearson RSB. Asthma-allergy and prognosis. Proc R Soc Med 1968;61:467-70.

10 Fry J. Profiles of disease. Edinburgh: Livingstone, 1966.

11 Blair H. Natural history of wheezing in childhood. $J R$ Soc Med 1979;72:42-8.

12 Alderson M. Mortality from malignant disease in patients with asthma. Lancet 1974;ii:1475-7.

13 Office of Population Censuses and Surveys, Royal College of General Practitioners, an Department of Health and Social Security. Morbidity statistics from general practice. Second Dational study 1970-71. London: HMSO, 1974. (Studies on medical and population subjects No 26.)

14 Office of Population Censuses and Surveys, Royal College of General Practitioners, and Department of Health and Social Security. Morbidity statistics from general practice. Second national study 1971-72. London: HMSO, 1979. (Studies on medical and population subjects No 36.)

15 World Health Organisation. Manual of the international statistical classification of diseases, injuries and causes of death: based on the recommendations of the ninth revision conference 1975. Geneva: WHO, 1977.

16 Berry G. The analysis of mortality by the subject-years method. Biometrics 1983;39:173-84.

17 Baker RJ, Nelder JA. The GLIM system, release 3. Oxford: Numerical Algorithms Group, 1978. f Chronic Dis 1978;31:619-24.

19 Alderson M Loy RM. Mortality from respiratory disease at follow-up of patients with asthma Br ₹ Dis Chest 1977;71:198-202.

20 Barbee RA, Dodge R, Lebowitz ML, Burrows B. The epidemiology of asthma. Chest 1985;87(suppl):21-5S.

21 Vena JE, Bona JR, Byers TE, Middleton E, Swanson MK, Graham S. Allergy-related diseases and cancer: an inverse association. Am $\mathcal{J}$ Epidemiol 1986;124:1004-11.

22 Meers PD. Allergy and cancer. Lancet 1973;i:884-5.

23 Hughes WF, Raitz RL. A comparison of cancer occurrence in allergic and non-allergic populations. Ann Allergy 1979;43:163-4.

24 Higenbottam TW, Feyeraband C, Clark TJH. Cigarette smoking in asthma. $B r f$ Dis Chest 1980;74:279-84.

25 Editorial. Fatal asthma. Lancet 1979;ii:337-8.

26 Eason J, Markowe HLJ A controlled investigation of asthma deaths occurring in hospitals in the North East Thames Region. Br Med F 1987;294:1255-8.

27 British Thoracic Association. Death from asthma in two regions of England Br Med $\mathcal{J}$ 1982;285:1251-5.

28 Stableforth D. Death from asthma (editorial). Thorax 1983;38:801-5.

29 Crompton GK, Grant IWB, Bloomfield P. Edinburgh Emergency Asthma Admission Service: report on 10 years' experience. BrMed f 1979;ii:1199-201.

(Accepted 21 September 1987)

\section{ONE HUNDRED YEARS AGO}

A law which shall make the disinfection of rags compulsory before they find their way into the hands of the workers in our paper mills is urgently called for by the outbreaks of infectious disease which from time to time occur among such persons. The village of Ivybridge, which has several times suffered from epidemics of small-pox conveyed by this means was, we are informed, the scene of a fresh outbreak on December 11th. Three girls, similarly employed, were attacked on the same day, and the local board of the village has decided to erect a building to be used as a hospital for such cases. We believe that rags are frequently disinfected by the owners of paper mills, but until it becomes a compulsory enactment the danger will continue. Now that the Local Government Board has shown that it recognises the risk, by the orders which it has from time to time issued during cholera epidemics forbidding the importation of rags, we trust that disinfection of these vehicles of disease will soon be made compulsory. (British Medical fournal 1887 ;i:28.)

The College of Physicians of Philadelphia celebrated the hundredth anniversary of its foundation on January 3rd. Dr S Weir Mitchell delivered a commemorative address in which he sketched the history of the College and the lives of the chief medical citizens of Philadelphia, among whom is numbered Dr Benjamin Rush, who was characterised by Dr Weir Mitchell as the greatest physician America has produced, and "next to Franklin, the greatest citizen of Pennsylvania." Edinburgh University was, he said, the parent of the Philadelphian College, though many of the most distinguished among its earlier members owed much to John Hunter. After the address a conversazione was held, and was attended by all the principal persons in Philadelphia. On the following day, Professor Stillé gave another retrospective address, and $\mathrm{Dr} \mathrm{Da}$ Costa welcomed a number of distinguished Associate Fellows elected in celebration of the centenary. Finally, after a luncheon had been discussed, and various toasts drunk, Dr Weir Mitchell brought the proceedings to a termination by reciting an ode entitled "The Doctor's Century," from which we may quote the concluding verses as given in the Philadelphia Medical Times:

"Perchance, as ghost consultants, we May stand beside some fleshly Fellow,

And marvel what on earth he means

When this new century's old and mellow.

Take then the thought-that wisdom fades, That knowledge dies of newer truth

That only duty simply done

Walks always with the step of youth.

A grander morning floods our skies With higher aims and larger light:

Give welcome to the century new, And to the past a glad Good-Night."

(British Medical fournal 1887;i:224.) 